\title{
Acción y muerte en la Antígona de Hegel
}

\author{
Berta M. Pérez ${ }^{1}$
}

Recibido: 15 de agosto de 2017 / Aceptado: 24 de marzo de 2018

Resumen. El objetivo de este artículo es ofrecer, al hilo de un análisis del texto de la Fenomenología del Espiritu que comenta la Antígona de Sófocles, una interpretación del concepto hegeliano de acción que pone en cuestión la tesis, defendida habitualmente, según la cual Hegel habría pretendido que el conflicto trágico resulta superado por la acción moderna (o el espíritu moderno en general).

Ese texto revela que la acción, que comparece ahí como principio absoluto, posee sin embargo una estructura quebrada y paradójica: necesariamente presupone $y$ niega una instancia en sí, inmediata y sustantiva que, finalmente, oculta la negatividad de la muerte. En la medida en que esa vinculación a la sustancia se demuestra así consustancial a la acción, el trabajo concluye, frente a otras lecturas, que, aun cuando la historia del espíritu haya dejado atrás la "sustancia ética" antigua, la acción (moderna) no puede liberarse para Hegel del carácter trágico. Por último, defiende el sentido en el que precisamente esta condición trágica la determina a la vez como destructiva y productiva, capaz de abrir la historia.

Palabras clave: acción; Antigüedad-Modernidad; espíritu; Idealismo alemán; libertad; sí-mismo; sustancia; tragedia.

\section{[en] Action and death in Hegel's Antigone}

Abstract. The aim of this paper is to offer, along an analysis of the passage on Sophocles' Antigone in the Phenomenology of Spirit, an interpretation of Hegel's concept of action that opposes the usual assumption that he had thought tragic conflict to be overcome by the development of modern action (or modern spirit).

This text reveals that action, though proving itself to be an absolute principle, possesses nevertheless a broken and paradoxical structure: it necessarily both presupposes and negates an immediate and substantive ground "in-itself" that in the end hides the negativity of death. By showing that this bond to substance is for Hegel essential to action, the paper argues against other readings that even if the ancient "ethical substance" is superseded in the history of spirit, (modern) action cannot free itself from this tragic character. Finally, I defend that it is precisely because of this very condition that action is destructive as well as productive, and hence able to open up history.

Key words: action; Antiquity-Modernity; German Idealism; freedom; self; spirit; substance; tragedy.

Sumario: 1. La Modernidad o la negación de la tragedia. 2. La tragedia griega en la historia del espíritu. 3. El mito de Grecia, o la sustancia ética. 4. La acción antes que la sustancia, o el hundimiento del mundo ético. 5. La acción antes que el sí-mismo, o el hundimiento del sujeto. 6. La acción y la muerte, o la muerte antes de la acción. 7. Inconsciente y destino: Grecia o el trauma de Occidente.

Cómo citar: Pérez, B.M. (2019): “Acción y muerte en la Antígona de Hegel”, en Revista Anales del Seminario de Historia de la Filosofía 36 (1), 107-126.

$1 \quad$ Universitat de València

bertamperez@gmail.com

ORCID: 0000-0002-6487-6058 


\section{La Modernidad o la negación de la tragedia}

La Modernidad filosófica es la época del sujeto. Lo que esto significa se puede expresar así: es la época en la que se establece y asume que el lógos del hombre, pensado y repensado a partir del yo pensante de Descartes, es el principio determinante -y aun constituyente- de la realidad. El género humano, en tanto que lógos subjetivo o lógos del yo, encuentra, pues, su verdad en su capacidad para dar o darse leyes, es decir, pautas que valen para los otros y/o para la realidad. Por supuesto la Modernidad entiende que esta capacidad nuestra para introducir tales cortes o decisiones o determinaciones en el tejido de lo real, esta libertad, está íntimamente unida a la capacidad aprehensiva o receptiva. Pero en todo caso, y aun cuando se llegue a ver -como se vio desde Kant- que ambas están presentes tanto en el actuar como en el conocer, es claro que se trata de dos facetas distintas: por un lado el sujeto "padece" la realidad y, por otro lado, la determina.

Se entiende así que la raíz de los problemas de este principio ("subjetivo", como lo llamaba Hegel en 1801) estribe en que tan esencialmente como le pertenece su capacidad para determinar y constituir la realidad, el mundo de sentido que son los otros y la naturaleza, le corresponde también el presuponerlos como una realidad que es en sí. Por un lado, como vieron los jóvenes idealistas postkantianos, se produce aquí una contradicción lógica o lingüística, en la medida en que la noción misma de "principio" se desmiente cuando la encarna una instancia que depende de otra cosa, de una sustancia o de un en-sí, o, dicho de otro modo, cuando el principio presupone una dualidad que lo contrapone a otra cosa. Pero además esta condición paradójica del sub-jectum, o fundamento, trae consigo para el hombre moderno muchas decepciones y mucho dolor.

Gran parte de la literatura y en general del arte del siglo xx se ha dedicado a expresar el sentimiento de impotencia e injusticia, el sufrimiento existencial del hombre que se autocomprende como sujeto moderno, autodeterminante, y se encuentra permanentemente desbordado y amenazado por una realidad extraña que acaba por desorientarlo y en ocasiones por hacerlo sucumbir. Pero ni siquiera hace falta esperar a la "tragedia" del individuo kafkiano, paradigmático en este sentido, al que la realidad en si de los otros, la ley, lo demuestra absolutamente privado de la capacidad de (auto)determinación, ni a la del Pierrot-le-fou de Godard, que ya no puede reconocerse en sus propias palabras, al que la realidad le ha arrebatado finalmente el lógos, para encontrar pruebas de las dificultades que ha atravesado el sujeto moderno para mantener legítimamente su posición, la posición del fundamento. Ya a finales del xviii el fracaso de la Revolución francesa desmentía en la realidad la promesa (de libertad) de la razón moderna, y las desventuras de la Justine del Marqués de Sade, burlada por los hombres todos y hasta por la ley de Dios, presagiaban dos siglos de crisis de las expectativas modernas.

Así las cosas, no ha resultado forzado buscar la respuesta de Hegel a esta "debilidad" del principio subjetivo en su negación de la inmediatez. Que no hay nada que podamos reconocer como inmediato, nada que se nos dé inmediatamente, significa que no hay nada más allá de la mediación del sujeto, y conlleva, en este sentido, la negación de cualquier sustancia o en-sí como tal, es decir, de toda instancia que se pretenda externa al lógos que determina, a su actividad determinante. Esta es la verdad de la afirmación según la cual Hegel entiende que lo absoluto es sujeto, o lógos. Por supuesto todo se juega en dirimir el sentido exacto que este sujeto 
que deviene absoluto tiene en Hegel, pero las lecturas más habituales han estado de acuerdo en que "en el fondo" se trata en todo caso de la razón moderna entendida como la lógica determinante del concepto (teórico). Distintas interpretaciones de Hegel, elaboradas a partir de premisas muy distintas, por ejemplo desde el marxismo por un lado y desde la hermenéutica por otro, vienen por eso a coincidir muy a menudo en que el pensamiento hegeliano, especialmente el del Hegel llamado "maduro", expresaría un intento de aliviar la decepción sufrida en la juventud, de disipar el escepticismo en el que pudieran acabar aquellos que experimentaron el fracaso revolucionario, o de atajar la desesperanza que pudieran sentir los lectores de Justine, asegurándole al lógos del hombre, al sujeto moderno, que ha encontrado por fin una encarnación -la del Estado moderno y a la vez la del saber de la Enciclopedia de las ciencias filosoficas - que domestica definitivamente la realidad hasta sus últimos recovecos y garantiza de este modo que ya nada se podrá escapar a su ley: no hay objeto exterior al sujeto, no hay ningún Otro que no se encuentre (en casa) ya en el espíritu objetivo, en la objetividad que se da a sí mismo el sujeto (absoluto), nada que no encuentre su lugar y su sentido en la exposición científica del saber. Diríase en este sentido que la decisión de remontarse a los presupuestos de la filosofía kantiana, la osada operación de rasgar el velo de la cosa-en-sí para descubrir que no hay nada tras ella que no sea nuestro propio reflejo, le habría permitido a Hegel creer poder entregarnos ya un panorama en el que nuestras acciones (racionales), en tanto que expresiones del lógos, dejarían de estar expuestas a sobresaltos o sorpresas, procurarnos, en definitiva, la victoria del lógos sobre toda sustancia.

Esta lectura es la que está en el trasfondo de aquellas interpretaciones de la posición de Hegel respecto a la tragedia, como la de Jean-Marie Domenach o Christoph Menke, que afirman que la dialéctica hegeliana, la absolutización de la actividad del lógos como fuerza negativa, opera como estrategia que conjura la tragedia ${ }^{2}$. Efectivamente, la comprensión clásica de la esencia de la tragedia -que necesariamente depende de su forma canónica en Sófocles y Eurípides- entiende que su rasgo principal consiste precisamente en la afirmación del poder irresistible e irreductible de la realidad -en tanto que sustantiva, en sí o independiente absolutamente de nuestra actividad- para imponerse sobre nosotros, para vengarse de las pretensiones de "determinación" del lógos. Esta visión es la que expone por ejemplo George Steiner en La muerte de la tragedia y en razón de la cual defiende que no cabe en verdad un pensamiento estrictamente trágico en la Modernidad, es decir,

\footnotetext{
Para Domenach la filosofía hegeliana constituiría la expresión más sofisticada del esfuerzo del sujeto moderno -que, en virtud de su abstracción, está acosado por un destino trágico- por liberarse de la sombra de la tragedia, en la medida en que para ello recurriría precisamente a la generalización absoluta de la misma contradicción trágica (cf. J.-M. Domenach, El retorno de lo trágico. Barcelona, Península, 1969, pp. 88 ss.). Y Menke -dando prueba de su adhesión a la dialéctica negativa de Adorno y al reproche que ésta hace a la dialéctica hegeliana por afirmativa o productiva- entiende también que Hegel no sólo comprende la Modernidad, en tanto que época de la "reflexión", como el tiempo que reacciona contra el conflicto irresoluble propio de la auténtica tragedia, sino que determina su propia filosofía como plenamente moderna en este sentido, es decir, que trabaja él mismo en la domesticación del conflicto trágico: el "sujeto autónomo" de Hegel superaría la tragedia por cuanto se demostraría capaz de "ordenar y controlar la facticidad de las diferencias trágicas" (cf. Ch. Menke, "Conflicto ético y juego estético". Enrahonar, 32/33, 2001, p. 221). Por último, yo misma he suscrito en el pasado esta visión al defender, por ejemplo, que la posición estética hegeliana en general no se habría hecho cargo del abismo trágico que Kant, en su tercera Crítica, vendría a reconocer como raíz del juicio estético y que Adorno habría heredado (cf. B. Pérez, "Hegel y la Critica del Juicio". Anales del Seminario de Historia de la Filosofia, 20, 2003, pp. 145-177). Es obvio que esta interpretación no se corresponde ya, al menos en este punto, con la que a continuación defenderé.
} 
en el marco teórico cristiano-racionalista en tanto que esencialmente orientado a establecer la confianza en que la realidad habla nuestro lenguaje ${ }^{3}$. De este modo, si la negación hegeliana de la inmediatez, de cualquier auténtico en-sí, se interpreta como absolutización del principio o del sujeto moderno, no puede extrañar que se presente a la vez como negación de la tragedia, del sentido y el sentimiento "pavorosos" de la tragedia ${ }^{4}$.

Y sin embargo esta conclusión respecto a los rendimientos de la filosofía de Hegel no puede dejar de resultar chocante cuando se la pone al lado del programa hegeliano, muy explícito en sus primeros escritos, de "destrucción del principio subjetivo", al lado de los muchos lugares donde Hegel insiste en el carácter "derivado", relativo, del sujeto moderno, donde niega que éste pueda constituir efectivamente el principio o lo ab-soluto, absuelto y libre, perfectamente autónomo, que busca la filosofía desde que es filosofía. Al leer con atención el programa del que despega su filosofía diríase, en efecto, incluso que, para Hegel, es precisamente el esfuerzo del principio moderno por someter a su otro lo que ha de ser abandonado definitivamente ${ }^{5}$. $\mathrm{Si}$, siendo este su punto de partida, el pensamiento de Hegel desembocase finalmente en la entronización de la razón en su determinación moderna (con sus pretensiones de absoluta determinación) como un todo perfectamente consistente y clausurado ¿no habríamos de tachar finalmente al propio Hegel de incoherente? ¿La negación

3 Sin duda la contraposición entre la concepción trágica del mundo y la cristiana-moderna encuentra su primera y más clara formulación en la obra de Nietzsche. El nacimiento de la tragedia expone ya la idea de que el "instinto dialéctico" de Sócrates abrió las puertas a una "consideración teórica" del mundo, la propia de Occidente, que se sostiene sobre la fe en que el saber (de la razón) cura, efectivamente, el dolor trágico (cf. F. Nietzsche, El nacimiento de la tragedia. Madrid, Alianza, 2002, pp. 25-38). Más recientemente, el análisis de la tragedia de Steiner -aun cuando rastrea en distintos momentos críticos de la Modernidad expresiones "trágicas" que rehacen y repiensan la tragedia (antigua)- deja ver desde su arranque que descansa también sobre la premisa de que la mitología cristiana, y en general la tradición judaica (en contraposición a la griega), es efectivamente antitrágica (cf. G. Steiner, La muerte de la tragedia. Barcelona, Azul, 2001, cap. 1).

4 Y ciertamente, en lugares como, por ejemplo, la última parte de sus Grundlinien der Philosophie des Rechts, dice Hegel que en el Estado moderno los individuos no conocen ya la tragedia: la racionalidad de lo real garantiza el "éxito" de su actividad (en tanto que racional) (cf. G. W. F. Hegel. Gesammelte Werke, Band 14.1. Hamburg, Felix Meiner Verlag, 2009, p. 133; en adelante: GW con indicación del volumen y la página). La acción del sujeto moral retratado por él -muchas veces como resultado de la clara oposición (kantiana) entre inclinación y ley, o del reconocimiento del carácter esencial del conflicto entre la particularidad y la universalidad de la acción en tanto que a la vez mía y sujeta a ley- aparece a menudo empañada por la sombra de las consecuencias que se le escapan, que hacen hueco a la sospecha de una realidad poco lógica, sorda a las intenciones del sujeto, pero pasajes como éste parecen dar a entender que sus desgarros serían superados en la esfera del Estado, en la acción del ciudadano cuyas intenciones particulares sólo son en tanto que mediadas en el todo ético. A primera vista, pues, el ciudadano hegeliano parece haber aprendido que, como sugieren también las Vorlesungen über Ästhetik, la tragedia es cosa del arte antiguo, ideal, "cosa del pasado". El propósito de este trabajo es defender que, aun cuando el texto hegeliano acepte y exprese esta idea de que el mundo moderno es profundamente antitrágico y se comprende como post-trágico, él mismo pone de manifiesto los límites de esta comprensión, es decir, que él mismo cuestiona la idea de que la tragedia de la acción pueda realmente ser dejada atrás.

5 En "Glauben und Wissen", por ejemplo, ese programa aparece fundamentado en la constatación de la falsedad de las presuntas victorias del principio subjetivo o moderno, del "principio del Norte", sobre su otro, y de las nefastas consecuencias que le ha comportado el menosprecio de su adversario, la ilusión de que su otro podría ser desterrado o domesticado (cf. GW 4, 315-324). Además, otros escritos de la misma época, o incluso anteriores, piensan las raíces y la política del mundo moderno a partir de una división interna claramente trágica. Si bien es cierto que en "Der Geist des Christentums und sein Schicksal" es el Judaísmo la religión que aparece como esencialmente trágica y el Cristianismo como aquella que pretende superar la tragedia en virtud del amor (cf. GW 2, 141 ss.), no se puede concluir, como señala Donougho, que para el Hegel de esos escritos la tragedia hubiera quedado de hecho neutralizada en el mundo moderno. Cf. M. Donougho, "The Woman in White: On the Reception of Hegel's Antigone". The Owl of Minerva, 21, 1, 1989, p. 67. 
de toda inmediatez no nos habría entregado a la postre una instancia perfectamente suturada que -con la excusa de no consistir sino en el todo de las mediaciones- sería en verdad idéntica a sí misma en todos sus puntos, dotada de diferencias que no son diferencias, de un movimiento que no es movimiento, de mediaciones que nada median? ¿No nos encontraríamos a la postre con serias dificultades para distinguir el sujeto absoluto ganado de una absoluta (o mera) sustancia?

En definitiva: ¿no justifica ese programa de partida, pues, una cierta resistencia a aceptar sin más esa tesis según la cual la "generalización" hegeliana de la negatividad sería en verdad el medio para dejar atrás la irresoluble contradicción trágica?

\section{La tragedia griega en la historia del espíritu}

Hegel discutió ciertamente la tragedia griega y, en la Fenomenología del espíritu, no sólo como genero artístico o como exponente de la crisis del arte "ideal", sino, al hilo de Antígona y en menor grado de Edipo Rey, como expresión de la verdad del espíritu en su "primera" forma, del mundo griego entendido como Sittlichkeit.

La protagonista de la Fenomenología es la conciencia finita que conoce o sabe en el elemento de la tensión moderna entre sujeto y objeto, que conoce siempre rota entre esos dos extremos y es, en este sentido, el principio subjetivo del mundo moderno. "El Espíritu" constituye el capítulo en el que el punto de vista absoluto mira a esa conciencia en tanto que se vuelve "consciente de sí misma como de su mundo y consciente del mundo como de sí misma" (GW 9, 238), en el que la mira en tanto que ella es en un mundo histórico o como mundo histórico. Dicho de otro modo: se expone en esa parte lo absoluto en tanto que se sabe en la historia o como historia, como lo absoluto, por tanto, del mundo cristiano-moderno. La historia como tal es, en efecto, el tiempo que corresponde al mundo moderno, y este capítulo es por ello una historia del sujeto moderno o, si se prefiere, una historia de la Modernidad en el doble sentido del genitivo ${ }^{6}$. La Grecia clásica, con el nombre de mundo ético, comparece aquí como su origen o su punto de partida, pero también como el mundo de la inmediatez, como mundo en el que la conciencia lo es sólo de la sustancia o sólo en tanto que inmediatamente ligada a la sustancia, si se quiere, como la expresión "natural" o "no espiritual" del espíritu, o como el momento "ahistórico" de la historia. Es en este sentido el límite interno del mundo moderno o de la historia. Es obvio que -al menos para Hegel- si el carácter "ahistórico" fuera el único requisito que habría de cumplir un pueblo para ser considerado el punto cero de la historia podrían serlo todos los que han precedido a Grecia, de modo que podemos deducir que si es el mundo griego el que resulta escogido para ocupar ese lugar es porque, además, la propia conciencia histórica moderna, la protagonista de la Fenomenología cuando se sabe histórica, reconoce en él su propio origen, lo pone como el punto cero de su historia.

Ponerlo o sentarlo así significa, pues, situarlo, por un lado, más allá de la historia, fuera de la historia, como un en-sí externo al movimiento histórico de la conciencia, pero también, por otro, erigirlo en el en-sí de esa historia, en el principio o el

6 En su interpretación del sentido en que Hegel comprende y supera el tiempo del mundo cristiano o moderno (a la vez que el griego) Malabou defiende que la historia (lineal) expresa un tiempo (o una concepción del tiempo) que presupone la tensión entre sujeto y objeto propia del principio subjetivo moderno que se autoexamina en la Fenomenología del Espíritu: cf. C. Malabou, El porvenir de Hegel. Avellaneda, Palinodia, 2013, pp. 39-44, 216-222. 
fundamento, el Grund, de la historia. Sólo Grecia, y ninguno de los otros pueblos que quedan fuera de ella, es el presupuesto, o la prehistoria, de la conciencia moderna.

La ambivalencia de este comienzo lo vuelve especialmente relevante, y a la vez problemático, a la hora de interpretar la visión hegeliana de la relación del mundo moderno, de su mundo, con Grecia y con la tragedia. De entrada resulta obvio que, como contrapunto de la Modernidad, Grecia sirve para clarificar negativamente su sentido: sin duda el sujeto moderno se ilumina aquí "contra" el trasfondo del espíritu griego en tanto que inmediato, natural o "prehistórico". Pero, también inequívocamente, este arranque expone a la vez el modo en que esa sustancia (espiritual), o ese carácter sustancial del espíritu, resulta precisamente liquidada, a propósito de la tragedia, por el propio espíritu: más allá de que se reconozca o no como habiendo tenido una existencia histórica, ese "momento" sustancial, se desmorona, ya también en el comienzo, para dar paso a Occidente.

Pues bien, desde la óptica de la mayoría de las lecturas de Hegel este pasaje, y la interpretación de la tragedia que Hegel hace en él, han de expresar finalmente su convicción de que el espíritu, en su marcha, se puede deshacer definitiva y perfectamente de su otro, de la inmediatez sustancial, del "resto" natural o, en general, de la suposición de un en-sí que pudiese marcarle un límite. Se entiende, en efecto, que la muerte de las individualidades heroicas (Antígona y Creonte), como acción que ha de ser finalmente imputada al espíritu, tiene el significado de una reconciliación que -además de expresar la fuerza unificadora del propio espíritupermite transitar de la unidad sustancial, que se ha demostrado inestable y frágil en virtud de su inmediatez o falta de "espiritualidad", a la unidad del espíritu que, como absoluta unidad de la mediación (conceptual o racional) de todas las diferencias, ya no podrá quebrarse a causa de ninguna. De este modo se identifica la raíz de la tragedia hegeliana con la inmediatez que aún no ha sido superada, con ese resto de "sustancia" todavía adherido en Grecia al espíritu y, consecuentemente, se apuntala la idea de que para Hegel el mundo moderno que se abre a partir de la tragedia podrá ser efectivamente un mundo libre de su amenaza. La negatividad de la naciente subjetividad trágica - en la que sin duda se expresaba ya la actividad del espíritu, aun cuando "fuera de tiempo", antes de que él encontrara su adecuada manifestación en la objetividad- se vuelve así verdaderamente productiva: su sacrificio sirve finalmente al derrocamiento de la perpetua paz del mundo ético o al nacimiento del mundo histórico que, liberado ya de su otro, no necesitará más héroes. Se da a entender, en definitiva, que para Hegel la tragedia se irá a pique en cuanto lo haga la inmediatez, en cuanto entremos en la Modernidad o en la historia propiamente dicha, o, dicho de otro modo, se interpreta que el desenlace de la tragedia pensada por Hegel es reconciliador en la medida en que viene a significar la superación de un mundo en el que aún cabía el conflicto irresoluble (o trágico) en otro en el que quedaría garantizado que toda oposición podrá ser mediada, superada ${ }^{7}$.

\footnotetext{
Cuando Steiner se vuelve en Antígonas a la lectura hegeliana de Antígona interpreta la oposición entre la ley de la familia y la ley del estado, entre Antígona y Creonte, como un dualismo que acontece desde y en el seno de la unidad del absoluto hegeliano. Así, la simetría que, para él, Hegel finalmente atribuye a esta dualidad funciona entonces como la garantía de que la maquinaria dialéctica que, poniendo en pie de igualdad (desde lo absoluto) todas las unilateralidades, permite progresar siempre hacia una unidad superior, pueda operar efectivamente aquí como medio del progreso y la formación racionales (cf. G. Steiner, Antígonas. Barcelona, Gedisa, 1986, pp. 35-58). La lectura de Butler resulta de entrada muy diferente en la medida en que antes que identificar el punto de vista hegeliano con el de una unidad que ya era antes de la oposición trágica, que equidista de sus dos lados, y que se recupera más madura y razonable en el mundo moderno, entiende que para Hegel finalmente
} 
En lo que sigue trataré de defender que el sentido en el que la Grecia aquí retratada (desde el punto de vista absoluto) es el en-sí del sujeto moderno no deriva únicamente de que ya ella reconociera a la autoconciencia como principio, de que reconociera-si bien de forma inadecuada por inmediata-el principio moderno, sino principalmente de que ella expone el carácter insuperable, esencial, del vínculo entre este principio y la inmediatez -entendida ésta como dimensión sustancial o incluso natural, es decir, como realidad que se considera siendo en sí (misma) ${ }^{8}$. En consecuencia, ese retrato, en la medida en que muestra que esa dimensión otra de la mediación espiritual (o subjetiva) no puede ser abandonada al modo de una adherencia, establece, a mi parecer, que la tragedia tampoco podrá ser para Hegel definitiva o absolutamente, en todos los sentidos, superada.

\section{El mito de Grecia, o la sustancia ética}

El primer momento del capítulo "El Espíritu" de la Fenomenología del Espíritu lo constituye "el espíritu verdadero" o "la eticidad" (die Sittlichkeit), es decir, Grecia. Se articula esta parte en tres secciones, la primera titulada "El mundo ético. La ley divina y la ley humana, el hombre y la mujer", la segunda titulada "La acción ética. El saber humano y el saber divino, la culpa y el destino", y la tercera titulada

el lado de Antígona, de la mujer o la familia, no está a la misma altura que el Estado, que -tras un aparente reconocimiento de sus derechos y valor de sujeto de la acción- no constituye en verdad un sujeto propiamente dicho, y que, en consecuencia, el desenlace del mundo antiguo y el origen del moderno se localiza en la victoria del lado masculino o político sobre el de la mujer. Sin embargo, también esta lectura nos lleva a inferir que en todo caso para Hegel la pretensión legítima del tiempo nuevo o moderno, aun cuando sea en virtud de un gesto claramente dominador, sería también la de borrar la amenaza del conflicto (que supone la voz de la mujer) (cf. J. Butler, Antigone's Claim. New York, Columbia University Press, 2000, pp. 1-14). Por último, otra interpretación clave y clásica de la comprensión hegeliana de la tragedia, y posiblemente la más conocida, la de Nussbaum, aun cuando parece haberse formado teniendo en cuenta únicamente los textos de las Lecciones de estética y en absoluto la Fenomenología del Espíritu, radicaliza todavía más la distancia entre la posición hegeliana y la perspectiva (eventualmente propia de Grecia) trágica en tanto que punto de vista para el que el conflicto es irreductible: hasta tal punto identifica sin más la solución hegeliana o su absoluto con la razón moderna (como razón unificadora y mediadora que a través del concepto supera las tensiones) que interpreta que la presentación hegeliana de la tragedia no sólo obedece a la intención de mostrar lo lejos que podemos estar o estamos ya de ella, sino además - pedagógica o constructivamente- lo mucho más racionales que podrían haber sido los propios protagonistas del mundo antiguo de cara a la consecución de un consenso armonioso (cf. M. Nussbaum, La fragilidad del bien. Antonio Machado Libros, Madrid, 2015, pp. 89-93, 105-124).

Donougho revisa la historia de la recepción de la interpretación hegeliana de la tragedia y señala algunas ingenuidades propias sobre todo de las lecturas filológicas que seguramente se podrían adscribir con el mismo acierto a Nussbaum. Señala además audazmente que el hecho de que Hegel presente a propósito de esta tragedia el escenario de un dualismo rígidamente simétrico no ha de entenderse como expresivo de su propio punto de vista, sino más bien del de la Grecia retratada, y que, lejos de asumirlo, Hegel más bien lo desmonta con su fino análisis. Por último se revuelve contra la idea - propia de las lecturas feministas- de que Hegel se identificara con el punto de vista del Estado (aunque sin duda era el dominador en el mundo retratado) y sancionara el sometimiento de la "locura" de Antígona: es obvio que para Hegel Antígona es la verdadera heroína y que lo es, por cierto, siendo la responsable de que también el Estado caiga. Sin embargo, resistiéndose así en varios lugares a una lectura "reconciliadora" de la interpretación hegeliana de la tragedia, parece decantarse finalmente por la asunción de que en todo caso, para el Hegel maduro, la conversión del "destino" en el "sí mismo particular" del mundo moderno expresa la confianza en la promesa cristiana de reconciliación, en el progreso formativo de la razón (cf. M. Donougho, "The Woman in White: On the Reception of Hegel's Antigone". The Owl of Minerva, 21/1, 1989, esp. p. 88).

8 Respecto al sentido de "natural" en Hegel estoy de acuerdo con Derrida cuando dice: "La naturaleza no es una esencia determinada, un momento único. Recubre todas las formas de la exterioridad a sí del espíritu. Por consiguiente aparece -desapareciendo progresivamente en ella- en cada etapa del devenir del espíritu" (J. Derrida, Clamor. La Oficina, Madrid, 2015, p. 45). 
"El estado de derecho". Esta última expone ya el irse a pique del mundo griego y su transformación en el derecho romano, mientras que los dos primeros exponen propiamente el ser del mundo griego.

Ya en las líneas que introducen el capítulo VI en general, "El Espíritu", y en las que presentan esta parte VI.A ("El espíritu verdadero. La eticidad") en su conjunto, antes de su división, deja claro Hegel que la "eticidad" es el espíritu en tanto que "verdad inmediata" (GW 9, 240) y que es en este sentido "sustancia simple" (GW 9, 240-241). Dice incluso que en cuanto sustancia es este espíritu "igualdad consigo mismo, carente de toda vacilación en su justicia" (GW 9, 239). Por eso, aun cuando desde la primera página se señale la ambivalencia inherente a la idea de un "espíritu" -una razón que se sabe una con la realidad o que se sabe a sí misma como un mundoque es, a la vez, "sustancial" - es decir, ajeno a la mediación propia de la conciencia-, no extraña que en la exposición del mundo griego que constituye esta parte VI.A aparezca, como su primera determinación, el momento sustancial (VI.A.a), y sólo después, el del movimiento de la acción (VI.A.b). Hegel dedica efectivamente casi diez páginas a exponer la constitución de la sustancia ética antes de abordar la acción griega al hilo de la tragedia de Antígona como si de su presupuesto se tratara. Y ciertamente este orden parece anticipar el que en la Enciclopedia, y por tanto en un contexto más general, colocará a la naturaleza como el presupuesto del espíritu y su historia.

Se comprende entonces que la interpretación más habitual de este texto concluya que para Hegel la historia del espíritu comienza con la pacífica unidad sustancial de Grecia que sólo después, en un estadio posterior, resulta desestabilizada por la inquietud de la acción. Ésta -retratada como trágica a propósito del "ejemplo" de Antígona- forzaría finalmente su desmoronamiento y daría paso a la configuración moderna del espíritu que inicia en Roma su andadura ${ }^{9}$. Por supuesto estas lecturas entienden así que la solución propiamente hegeliana, la verdad de su historia, la expone este espíritu moderno y no la sustancia antigua, pero entienden también que el propio Hegel, colocando en el origen de la historia esa unidad sin fisuras, nos deja ver ya que la verdad del propio espíritu está en su unidad o su identidad: la sustancia ética habrá de ser superada por cuanto en ella -por inmediata- la unidad todavía no ha expresado todo su poder, pero su carácter unitario, la prioridad de la unidad que ella expresa, eso será precisamente lo que no se supere, lo que "conserve" el espíritu (histórico). Por eso son estas interpretaciones cómplices de la idea general de que el tránsito hegeliano de Grecia al mundo moderno significa para Hegel en todo caso la ganancia de un mayor y más profundo (o más sutil) dominio de la unidad de lo absoluto, y de que está orientado, en consecuencia, a conjurar el trágico conflicto griego $^{10}$.

9 Tanto Steiner como Marrades parecen asumir, en efecto, que sólo por la acción histórica de ciertas individualidades excesivas la hasta entonces armoniosa relación entre familia y Estado, recogida en la unidad del mundo ético, se transforma en un conflicto, suscribiendo así ímplicitamente la idea de que -si no en el orden cronológico, sí al menos en el lógico- para Hegel es antes la unidad que la oposición (cf. G. Steiner, Antígonas. Barcelona, Gedisa, 2000, 46-47; J. Marrades, El trabajo del espíritu. Madrid, A. Machado Libros, 2001, esp. pp. 360-373). El alfa y omega de la historia es, para estas lecturas, el espíritu absoluto entendido ciertamente como identidad (dotada de movilidad dialéctica): por eso en un primer momento, cuando la negatividad subjetiva (Antígona misma) es sólo destructiva, cuando todavía no está recogida propiamente en la unidad de un sujeto "formado", vence la sustancia (sobre la individualidad) y por eso, en un segundo momento, cuando esa negatividad se recoge ya en la unidad del sujeto en formación, se desmorona definitivamente.

10 Cf. nota 2. 
Ahora bien, es obvio que si las cosas fueran simplemente así, si para Hegel primero fuese la sustancia ética y luego la acción o más en general primero el en-sí y luego el para-sí o primero la naturaleza y luego el espíritu, tendríamos que concluir que estaría sorteando el problema que en principio él, y en general el Idealismo alemán, pretende resolver, esto es, precisamente el de la unidad y la articulación que necesariamente ha de vincular la naturaleza al espíritu o la sustancia al sujeto ${ }^{11}$.

En las mismas primeras páginas que introducen este capítulo se explicita que la conjunción del carácter espiritual o consciente por un lado y el carácter inmediato o sustancial, por otro, es hasta tal punto esencial al mundo ético que hace no sólo que Grecia se "divida" en sustancia y autoconciencia, sino también que su sustancia se divida a la vez en dos esencias o dos poderes. Y es esta constitución escindida entre familia y estado de la sustancia ética lo que de hecho vendrá a exponer el primer apartado de "La Eticidad", el que precede a la acción trágica y que ayuda sin duda a comprenderla. Pero más que vindicar que de alguna manera el presupuesto de la acción de la autoconciencia, la sustancia, cuenta ya con una grieta que hace posible el desgarro que aquella introducirá, me importa poner al lado del orden del texto, de su índice, la insistencia de Hegel, desde la primera línea que introduce "El espíritu verdadero", en que, por muy sustancial que sea este mundo, es en todo caso espíritu y tiene, por ello, su origen en la acción, en que por tanto la eticidad misma, la sustancia ética misma, es el producto de la acción. Es la acción la que separa o divide al espíritu en sustancia y conciencia de esa sustancia $-\mathrm{O}$, si lo preferimos, espíritu propiamente dicho- $(\mathrm{cf} \text {. GW 9, 242-243 })^{12}$. Pero entonces, si realmente la acción es antes que la sustancia, ¿a qué responde el orden del texto?

A mi parecer el propio texto lo explica: en las páginas dedicadas a la acción Hegel insiste, tanto como ha insistido en su prioridad ontológica, en que la autoconciencia que le corresponde se sabe inmediatamente una con la esencialidad ética, con el todo de la eticidad o con sus leyes (GW 9, 251). Es, pues, para el espíritu griego, para la propia conciencia griega que se sabe y actúa (o para la conciencia griega que aquí se retrata y que, como dije más arriba, es la que corresponde a la representación moderna) para la que la sustancia es lo primero. Es el "agente" mismo el que se autocomprende como la conciencia de la sustancia. Pues bien, dado que Hegel pretende exponer la verdad de la acción propia del mundo ético y sabe que la propia realidad de esta acción depende de esa autocomprensión, presenta, efectivamente, la sustancia como condición de la acción ${ }^{13}$. La unidad de ese mundo sustancial, del

11 Como es bien sabido el Idealismo post-kantiano, partiendo de la convicción de que un auténtico principio (o fundamento, sub-jectum) ha de poder dar cuenta del todo de lo real desde sí mismo o, dicho de otro modo, de que ha de ser absoluto, nace combatiendo la "cosa-en-sí" kantiana en la medida en que expresa precisamente la existencia de un otro perfectamente desvinculado del principio o sujeto, en la medida en que expresa la asunción de la imposibilidad de dar cuenta del tránsito (y por tanto de la unidad) del sujeto a su otro. Todo su programa consiste por ello en el esfuerzo por transitar (o hacer transitable) un camino que ligue los extremos opuestos en Kant. Por las mismas razones es obvio para la filosofía post-kantiana que si el punto de partida no fuese ni siquiera un sujeto finito (frente a un sujeto absoluto), sino la sustancia misma, entonces el tránsito resultaría a todas luces imposible (véanse a este respecto las críticas tanto de Schelling como de Fichte a la posición "dogmática" o spinoziana: cf. F. W. J. Schelling, "Philosophische Briefe über Dogmatismus und Kriticismus", en Historisch-kritische Ausgabe, vol. I, 3. Stuttgart-Bad Cannstatt, Frommann-Holzboog, 1982, pp. 79, 88; J. G. Fichte, "Zweite Einleitung in die Wissenschaftslehre", en J. G. Fichte-Gesammtausgabe der Bayerischen Akademie der Wissenschaften, vol. I, 4. Stuttgart-Bad Cannstatt, Frommann (Holzboog), 1970, p. 221).

12 Ya al introducir el Capítulo VI como un todo, dice Hegel: "Diese Substanz ist ebenso das allgemeine Werk, das sich durch das Thun Aller und Jeder als ihre Einheit und Gleichleit erzeugt" (GW 9, 239).

$13 \mathrm{Y}$ es también en este sentido en el que Hegel dice que no hay una acción propiamente individual en Grecia, es 
Reich der Sittlichkeit, es, pues, de hecho, presupuesto de la acción griega, pero lo es porque es el en-sí o el fundamento ("der Grund": GW 9, 251) del que ella parte, es decir, porque lo es para ella.

Con esto quiero destacar en primer lugar que lo que Hegel retrata en este capítulo es en todo caso una autoconciencia o autocomprensión, un punto de vista, que incluso el retrato de la sustancia inmediata responde al interés por retratar fielmente el punto de vista asignado a Grecia, es decir, el de la inmediatez. Prueba de ello, y de que por tanto la conciencia que actúa o la acción autoconsciente es, para Hegel, antes que la sustancia, es que la propia descripción de la identidad de la sustancia la presenta ya -además de doble- como una re-acción a su trasfondo, como investida, pues, por una fuerza o una mirada activas. Del mismo modo que la acción griega es contra un trasfondo que se vuelve absolutamente externo, la familia es ya siempre, incluso en tanto que sustancia, contra la muerte natural (cf. GW 9, 244-245), y el estado, la esfera sustancial que corresponde propiamente a la autoconciencia, ya siempre contra la familia, la esfera propiamente sustancial o, si se quiere, la cara más "natural" de la sustancia ética, y a la que él determina sólo negativamente, como lo que él no es, como el espacio de la in-mediatez y de la in-consciencia (cf. GW 9, 242; GW 9, 258). El ser de Grecia, en definitiva, se retrata en tanto que deriva de su acción y su saber (y no-saber), y no a la inversa.

Pero, además, Hegel dice también que la sustancia es este fundamento por constituir el trasfondo contra el que la acción es. Es decir, la sustancia griega aparece antes de la acción no sólo porque ésta, o su autoconciencia, se entienda como una con lo real, sino también porque sólo se afirma (y en la autoafirmación consiste su ser) en tanto que se destaca y distingue de ella, en tanto que la niega: el índice del texto no refleja únicamente el carácter originario que la unidad sustancial tiene para la acción griega, sino también la nítida separación y oposición que ésta necesariamente establece entre sí misma y su presupuesto. La sustancia inmediata es el presupuesto del punto de vista griego y es presupuesta desde el principio como algo externo al propio punto de vista, como lo otro de ese punto de vista.

Ya en los escritos previos a la Fenomenología, Hegel había analizado este punto de vista de la inmediatez, si bien refiriéndose en ellos a la Modernidad prekantiana. Tachaba ahí de inmediatas aquellas concepciones que habían entendido la unidad como unidad indivisa, libre de toda diferencia, y que, por ello mismo, se habían visto forzadas a determinar la diferencia como oposición absoluta, como la dualidad donde cada uno de los miembros "es una nada para el otro". Ambas representaciones (la de la unidad inmediata y la de la oposición absoluta) son para él, en efecto, la cara y la cruz de una misma figura: expresan una comprensión, un modo de relacionarse consigo, y por tanto con el mundo, en el que se niega cualquier tipo de mediación. Así, su narración retrata la Grecia mítica como indivisa unidad sustancial, pero expone también el modo en que a ella le pertenece la negación de su propia identidad, esto es, su autonegación (como mito). El "espíritu-como-sustancia" o la figura sustancial del espíritu sólo es -en tanto que "primera" forma del espíritu, en tanto que espíritu recién nacido- el "no" a la sustancia (o a la naturaleza), en verdad su ser solamente consiste en esta negación. Hegel sabe, pues, que la sustancia es obra de la acción y que la acción sólo es como negación de la sustancia. Esta es la paradoja que se viene a aclarar a propósito de la acción.

decir, que la acción es ejercida por roles, por normas vivas, inscritas en la propia sustancia (véase, por ejemplo, GW 9, 253). 


\section{La acción antes que la sustancia, o el hundimiento del mundo ético}

Hegel inicia el apartado b de VI.A introduciendo la acción como un momento que, casi al modo de un accidente evitable, de una tragedia evitable o incluso de un acontecimiento anacrónico, ajeno al mundo antiguo, viene a perturbar el orden, el perfecto equilibrio y la paz, del mundo ético (cf. GW 9, 251). Ratifica así de entrada la representación de Grecia como sustancia desconocedora de cualquier inquietud. Pero, inmediatamente, procede a explicar la estructura de esa acción que le vendría a "acaecer" a partir precisamente del deber, es decir, de esa conducta que, siendo la de los roles, está perfectamente atada a la sustancia, que es la acción de la sustancia ética. Se explica, pues, la acción griega, que va a ser la de Antígona, a partir de esa identificación in-mediata, absoluta, de conciencia y sustancia.

Por un lado, Antígona, en la medida en que entiende su acción como el seguimiento de una pauta sustancial, se ve arrastrada a la negación, también inmediata, de cualquier diferencia u otredad que aparezca. Si se quiere, a ponerla como externa o ajena, a no reconocerla. Identificada absolutamente con lo que para ella es la sustancia, con la familia y su ley, no puede, en principio, entender la diferencia de la ley del Estado más que como un "accidente" de la sustancia. La división de la sustancia o de la ley sólo puede ser para ella, en efecto, un infortunio externo ("eine unglückliche Collision": GW 9, 252). Pero por otro lado, precisamente en virtud del carácter absoluto que esa unidad tiene, precisamente porque no puede ser dejando algo fuera de sí, Antígona habrá de reconocer esa división o ese otro como parte de la identidad a la que ella misma pertenece. Tampoco podrá dejar de reconocerla auténticamente, es decir, como propia. Ella sabe que su identificación con la sustancia, su confianza en su identidad con ella, y por tanto en la identidad de su saber con la realidad, en que la realidad de su acción, la Tat, expresará perfectamente su saber o su conciencia, le impedirán sobrevivir a esa división del mundo ético que, precisamente a propósito de su acción, se le pone de manifiesto. Ésta es la contradicción trágica comprendida en términos hegelianos.

Desde esta doblez del punto de vista de la inmediatez -en la medida en que expresa ese re-negar o esa represión de lo diferente y a la vez la exigencia de reconocerlo como propio- Hegel dará cuenta también del efecto traumático que la acción tiene para la conciencia, del modo en que fuerza el encuentro con lo no-sabido o con el inconsciente - de forma especialmente clara en el caso de Edipo, pero también, de otro modo, en el de Antígona ${ }^{14}$. Pero en este apartado b sobre die Sittliche Handlung, en cuyo comienzo Hegel parece narrar, como en una novela (moderna), que primero era la calma y luego llegó la acción, en lugar de detenerse a explicar cómo Antígona provoca y padece la verdad alumbrada, en lugar, pues, de analizar la acción a partir de la experiencia de Antígona, señala más bien que la acción por sí misma desvela la eticidad como el movimiento negativo, de mutua exclusión, de sus dos lados sustanciales - la familia y la polis- en tanto en cuanto retrotrae a ambas esencias (Wesen) al abismo (Abgrund) del "temible destino". Se presenta la acción como un golpe o un vuelco en virtud del cual cada esfera sustancial se prueba como "la nihilidad (Nichtigkeit) de sí misma y de la otra" y en el que, de este modo, el propio

14 "Die Wirklichkeit [...] zeigt sich dem Bewußtseyn nicht, wie sie an und für sich ist, - dem Sohne nicht den Vater in seinem Beleidiger, den er erschlägt; - nicht die Mutter in der Königin, die er zum Weibe nimmt." (GW $9,255)$. 
fundamento o presupuesto de la acción, la sustancia inmediata, se va a pique (GW 9, 251). No cabe afirmar más claramente que la acción no sólo presupone la sustancia, sino que es ya siempre negándola, en la forma de su negación. Hegel toma pues la palabra y dice en voz alta lo que Antígona no sabe o no quiere saber: no sólo que ella, su acción, niega el Estado o la diferencia, sino que niega la sustancia misma, la identidad misma que mueve su acción. El lugar desde el que Hegel habla ya no parece coincidir, pues, con el de la autoconciencia griega. Ha dejado de ser el mero portavoz del punto de vista de la inmediatez para mirarlo ahora desde fuera, para poner sobre la mesa explícitamente su límite, su contradicción.

$\mathrm{Y}$ es entonces cuando se pone de manifiesto completamente que el en-sí que presupone la acción, la sustancia, efectivamente, no ha sido contemplado en este capítulo como siendo en-sí propiamente, como siendo realmente antes de la acción: se nos está confirmando que, antes bien, ella nunca es, nunca ha sido, sin ser a la vez negada como tal fundamento o como tal presupuesto por la propia acción. En el arranque del capítulo ya se había dicho: la acción es lo primero, la sustancia es su obra. Más allá de la acción, al margen de la acción, la sustancia es sólo mito, fantasma externo a la vida y al tiempo, porque sólo la acción es vida y porque sólo ella abre el tiempo.

Así que el texto de Hegel no sólo expone cómo la acción trágica revela a su sujeto, a la autoconciencia o el sí-mismo, a Antígona si se quiere, que el fundamento no era "auténtico", que no era la unidad sin fisuras que él presuponía, sino que nos dice además que en toda acción el propio fundamento de la misma, su propio presupuesto, se va a pique. Y le indica así al lector que el en-sí que se ha presentado antes de la acción como su presupuesto no era otra cosa que el presupuesto puesto (gesetzt) por ella, nada más que un postulado suyo: la noción misma de en-sí, de un fundamento previo a la autoconciencia, al espíritu como conciencia y acción, se va a pique. La naturaleza, la sustancia o el carácter sustancial del espíritu sólo ha comparecido en este capítulo en tanto que postulado o, si se quiere, ficción de la conciencia que actúa, de la acción espiritual misma. El mito del mundo ético como unidad sustancial, previa e independiente de la acción, se desmorona. El capítulo VI de la Fenomenología habla por tanto desde su comienzo solamente de la historia y de la acción, es desde su comienzo tiempo moderno, el tiempo del espíritu o el tiempo sabido $^{15}$. Y entonces, si esto es así, parece que también empieza a desdibujarse la presunta diferencia que separa nuestra acción, la acción de los modernos, de la que aquí se analiza, la distancia que presuntamente media entre el sujeto que aquí actúa y el sujeto moderno ${ }^{16}$.

Se afirma, además, en ese pasaje que son los dos poderes éticos, en tanto que sustanciales, los que se van a pique, es decir, que es la propia contraposición del mundo ético en tanto que división sustancial la que se disuelve. Hegel está confirmando, pues,

15 En este punto estoy de acuerdo con Žižek, que cifra la superioridad de Hegel sobre Schelling en el modo en que el primero logra transformar el lenguaje para introducir a su otro, el otro de la historia, en su interior, para hacer justicia a la verdad de ese otro sin tener que recurrir ya a un lógos mitológico, sin tener que tratar a ese otro como si verdaderamente fuera un en-sí más allá del lógos: cf. S. Žižek, El resto indivisible. Buenos Aires, Ediciones Godot, 2013, Parte I, cap. II, esp. pp. 169-175, 205-223.

16 ¿Acaso no reconoció el propio Kant que la acción, especialmente la acción libre, la acción más libre que podamos pensar modernamente, la que sólo quiere dar cuenta de su ser de la razón, de su naturaleza racional, ha de presuponer necesariamente un en-sí? Véase, por ejemplo, I. Kant, Kritik der praktischen Vernunft. Akademie Ausgabe. Berlín, Reimer, 1913, vol. V, pp. 6, 43; también I. Kant, Kritik der reinen Vernunft, A 494/B 522. Akademie Ausgabe. Berlín, Reimer, 1904, vol. III, p. 341. 
que no se trata de que la dualidad de la sustancia estuviese preparando, posibilitando, el desgarro de la acción, sino de que -insisto, tal como afirma la tesis planteada al principio del capítulo- es el desgarro de la acción el que está a la base de esa grieta. El mundo ético, y con él su división en dos poderes, es obra de la acción. El ser doble de la sustancia ha sido reconducido por fin a casa, a la acción de la autoconciencia. Al probarse ésta capaz de desmontar la contraposición sustantiva, ha demostrado en efecto que ésta era sólo un montaje suyo, que la escisión originaria es en verdad suya, que es ella misma ("Das Thun ist selbst diese Entzweyung": GW 9, 254)"

\section{La acción antes que el sí-mismo, o el hundimiento del sujeto}

Esa interpretación de la acción como contragolpe, como el golpe que se vuelve contra el propio fundamento, como el desgarro que presupone y destruye su presupuesto, está sin duda a la base de la fina lectura que Hegel hace del argumento de Antígona, pero, más allá de ello, se revela como la estructura de la acción en general, y permite así ver el sentido en el que, para él, la tragedia de Antígona expresa ya la esencia de la acción. Para empezar, se presenta incluso antes de que se encarne en el caso de Antígona, es decir, como la forma de la acción en la que -según se nos ha dicho al comienzo del capítulo- consiste el espíritu desde que nace, en cuanto nace. Pero, además, se ha puesto de manifiesto que es esta estructura la que explica que la acción, o el espíritu, sea verdaderamente el principio que puede dar cuenta de todo, de sí y de lo otro. Se ha puesto de manifiesto que esa estructura es la del principio del capítulo VI en general, la del obrar espiritual y no únicamente la de una de sus figuras.

El drama de la chiquilla que se sabe una con la ley una de lo real y resulta enfrentada a una realidad dividida en sí misma, es reubicado en el seno de una autoconciencia o un sí-mismo o, incluso, un espíritu, cuya contradictoria actividad exige la unidad de lo universal a la vez que, contraponiéndose a ella, la vuelve imposible, que se eleva a una ley universal, que pone como sustancia, a la vez que se enfrenta a ella como símismo. Ser como espíritu (como conciencia que actúa) es ya siempre, efectivamente, afirmarse elevándose a la universalidad de una instancia "sustancial" que, habiendo de valer para todos, me trasciende, $y$, en consecuencia, ya siempre me niega (como particular) ${ }^{18}$. $\mathrm{O}$, visto desde el otro lado, actuar es siempre afirmar la universalidad (de una ley), pero también determinarla como encarnada en este acto particular y, en esa medida, negarla en tanto que verdadera ley (verdaderamente una y universal), convertirla en una ley particular que excluye otra ley posible. Cabe decir: toda acción pone ya siempre dos leyes, la que cumple y la que infringe. El caso Antígona muestra, pues, para Hegel cómo el actuar propiamente dicho, el poner una norma universal como la base o "razón" (Grund) de un acto -si se quiere, el darse una ley en el sentido kantiano-, es siempre un apropiarse esta norma, una negación de su ser

17 Entiendo que la tesis adorniana según la cual Hegel se levanta sobre su época y la nuestra (al menos sobre la actualidad de la fenomenología) en virtud de su radical y absoluta negación de la inmediatez encuentra confirmación también en este texto. No se trata a mi parecer, en efecto, de una tesis meramente epistemológica: cf. Th. W. Adorno, "Contenido de experiencia" en Sobre la metacrítica de la teoría del conocimiento. Tres estudios sobre Hegel. Madrid, Akal, 2012, pp. 269-296.

18 Derrida, por ejemplo, insiste una y otra vez en la paradoja de esta estructura, en la autonegación que conlleva la afirmación del propio ser, como la forma misma del espíritu hegeliano en general: véase J. Derrida, Clamor. Madrid, La Oficina, 2015, por ejemplo p. 15, p. 20. 
fundamento en sí o independiente de mí y, por ello, un crimen. Hegel lo dice así: la acción es siempre crimen (Verbrechen), entraña siempre culpa (Schuld) (cf. GW 9, 254).

Llegamos así a la paradoja de un principio endeudado, cargado de deuda (Schuld). En efecto, la comprensión hegeliana de la acción dice por un lado que ella es el origen de su fundamento o su en-sí, de su sustancia o su ley. Y, en este sentido, la erige, pues, en principio absoluto, si se quiere, en el sujeto absoluto. Pero, por otro lado, dice también que la acción no es nada antes de este poner ese otro para negarlo, que ella es ya siempre, desde que nace, como su negación. Y, en este otro sentido, coloca el propio origen de la acción en la necesidad de negar ese presupuesto, fundamento, o en-sí, reconociendo por tanto que depende radical y originariamente de ese otro, que está ya siempre condicionada, endeudada ${ }^{19}$.

Es esta constitutiva dependencia de lo absoluto respecto a un afuera lo que permite resistirse a interpretar la prioridad de la acción sobre la sustancia que hemos defendido en el apartado anterior como la simple afirmación de que la identidad del sí-mismo es ya antes de la sustancia. En lo sucesivo trataré de mostrar, frente a lecturas como las mencionadas más arriba, que la negación de la sustancia que la tragedia de la acción lleva a cabo no expresa la impecable victoria de un sujeto que se liberaría de todo lazo sustantivo y que, aun cuando no pudiera ser celebrada a estas alturas de la historia por Antígona (apegada aún a la sustancia), pronto lo sería por el sujeto moderno ${ }^{20}$.

Para ello resulta esencial entender el modo y el porqué del sucumbir de Antígona. Antígona sufre la tragedia no cuando la sustancia o la ley, en su doblez, destruye su individualidad viva, sino en el mismo momento en que la sustancia se va a pique. Sucumbe entonces verdaderamente porque se hace cargo radicalmente del significado de que la ley o la sustancia que se va a pique es suya, a saber: que ella, como sí-mismo, sólo es en tanto que una con la sustancia, del mismo modo que la familia sólo es en tanto que una con el estado ${ }^{21}$. Lo que la Antígona de Sófocles pone al descubierto para Hegel, por tanto, es que la acción, al manifestarse como el "principio" de la sustancia y de su división, se revela a un tiempo como el origen de la división entre sustancia y sí-mismo (Selbst) y, así, finalmente, también como el origen escindido de la autoconciencia (que se contrapone a la ley o a la realidad): sustancia y sí-mismo nacen y cuelgan del mismo desgarro de la acción. La nihilidad de la sustancia que la acción descubre (cf. GW 9, 251) es en realidad, pues, la

19 Si tenemos en cuenta, como señala Derrida (op. cit., pp. 183-185), la peculiaridad que es propia para Hegel del vínculo hermano-hermana en tanto que relación natural en la que la universalidad no consiste en la abstracción de la mera "reemplazabilidad", sino que es más bien la de la singularidad del para-sí que nace del ser reconocido por otra autoconciencia, podríamos ya anticipar que al escoger la acción de Antígona qua hermana para explicar la acción -o el principio del capítulo VI en general o el principio de la historia que acoge también a GreciaHegel está ya señalando que de la acción será constitutiva su relación con la inmediatez. La hermana es en efecto el lugar de la familia (sustancial, divina o inmediata) donde ya se está llevando a cabo el paso de la ley divina a la ley humana.

20 Me refiero a las interpretaciones señaladas en las notas 1 y 6.

21 El momento central es en este sentido aquel en el que Antígona duda de su propia inocencia ante ese otro que su acción ha negado porque reconoce a ese otro como propio. Dice Antígona: "Ciertamente, con mi piedad me gané un trato impío. Si esto es lo justo entre los dioses, escarmentada, podré reconocer que he errado" (vid. Sófocles, Antígona. Edipo Rey. Electra. Barcelona, Labor, 1975, p. 63). Hegel mismo traduce este última verso así: "weil wir leiden, anerkennen wir, daß wir gefehlt -". Y lo introduce diciendo: "Das sittliche Bewußtseyn muß sein Entgegengesetztes um dieser Wirklichkeit willen, und um seines Thuns willen, als die seinige, es muß seine Schuld anerkennen" (GW 9, 253-254). 
nihilidad del en-sí o de la identidad de un fundamento en general, y de ese modo también la del sí-mismo, la del "otro" fundamento de la acción ("Damit aber gibt das Handelnde seinen Charakter und die Wirklichkeit seines Selbsts auf, und ist zugrunde gegangen": GW 9, 256).

Hegel dice ahora, pues, que también el sí-mismo es obra de la acción: en su contragolpe se niegan (y afirman como presupuestos) a un tiempo sustancia y sujeto, en-sí y para-sí. Porque nacen ambos de la acción, sólo ella los depone, los conduce "a la nihilidad de sí mismo y de lo otro". Sólo ahora tenemos la visión completa del contragolpe de la acción y por eso sólo ahora se consuma la tragedia o se descubre el terrible destino en la extensión de todo su poder: "Erst in der gleichen Unterwerfung beider Seiten ist das Absolute recht vollbracht, und die sittliche Substanz als die negative Macht, welche beide Seiten verschlingt, oder das allmächtige und gerechte Schicksal aufgetreten" (GW 9, 256). De modo que, frente a la interpretación tradicional, es fácil constatar que la fuerza responsable de la tragedia, la que se impone finalmente sobre los dos lados del conflicto, no es la identidad de principio alguno, ni la de la sustancia ni la de la conciencia: que ni Antígona se desmorona trágicamente a manos de la identidad inmediata de la sustancia antigua, ni el mundo ético lo hará luego a manos de la identidad mediadora del sujeto moderno ${ }^{22}$. Lo que aquí se impone es un poder negativo y ciertamente absoluto, el terrible destino. ¿Pero de donde viene este tercero que se yergue entre y sobre los opuestos al modo de un enigma?

Formularemos la pregunta de otro modo, abordándola desde el lado de la acción. El espíritu, o la acción, es absoluto en el sentido de que no depende de ningún fundamento determinado, del contenido de ningún en-sí -el contenido de toda ley es puesto por el espíritu y destruido por él en cada nueva experiencia, en cada acción-, y sin embargo, en la medida en que sólo es en respuesta a él, depende de él radicalmente. Todos los dioses son suyos, puestos y depuestos por él, pero: ¿de dónde le viene la necesidad de poner dioses? ¿Qué dios es ése que nos obliga a ponerlos y honrarlos, a ponerlos como nuestro fundamento? ¿Quién es ese otro del espíritu o de su acción?

\section{La acción y la muerte, o la muerte antes de la acción}

Tras exponer la estructura completa del "contragolpe" que es la acción al hilo del caso de Antígona, una vez, pues, que resulta ya del todo insoslayable la pregunta por ese otro al que ha ofendido Antígona - pero también Creonte-, la familia -pero también el estado-, y que no retorna como una identidad sustancial, sino, en todo caso, como la negatividad de un terrible destino, por ese otro que ha de estar incluso antes del principio de la acción, Hegel opta por volverse desde la acción de Antígona a la de Polínices, pasando por la de Creonte. El recurso a la genealogía expresa de nuevo el carácter problemático de la acción en tanto que principio (es el origen de todo, pero presupone siempre un otro y es así ya siempre re-acción), pero sirve sobre todo para reconducir la acción a un conflicto originario del espíritu o el sí-mismo

22 La lectura tradicional defiende en verdad ambas cosas: que en un primer momento vencería la sustancia sobre Antígona y Creonte, y que en un segundo momento lo haría el sujeto sobre Grecia, es decir, que vencería en todo caso la identidad. 
con la falta de conciencia y la contingencia de la naturaleza. En el comienzo se encuentra la exigencia de unidad del Selbst que no puede soportar la contingencia de que, en su lugar, la naturaleza haya puesto dos hermanos (en lugar de uno) (cf. GW 9, 257). Así que en el origen del origen está la incapacidad del espíritu para tolerar la contingencia e inconsciencia de la naturaleza. Es esta misma intolerancia lo que explica, en efecto, que Antígona no pueda dejar que la muerte de Polínices permanezca como una mera muerte "natural", y, en general, que la familia misma - cuya ley ella expresa- se constituya a partir del deber de dar sentido a la muerte en tanto que hecho natural, mudo y contingente, a una "acción" que no es tal porque no es de nadie, porque no expresa ningún saber ni ninguna ley. Eso dice Hegel de la familia al presentarla en el primer apartado de "la eticidad" como presupuesto de Antígona, pero sobre todo dice, también ya allí, que ese deber de negar la muerte expresa una exigencia que es propia del espíritu en general, también del Estado, que vincula, pues, al Estado y la familia, precisamente porque la muerte los trasciende y los niega a ambos (cf. GW 9, 244).

Tratando aún del mundo ético, Hegel ya había introducido, pues, la acción, el principio del espíritu, como la actividad creadora, positiva, de dar sentido. El envolver la muerte en un rito, el darle un nombre y un sentido, coincide entonces con el (im-)poner (sobre ella) una ley y unos dioses, un fundamento (en primera instancia y, desde luego, en el caso de Antígona, la ley de los Penates) (cf. GW 9, 244, 249-250). Y, a la vez, también allí, Hegel anticipaba ese otro lado de la acción explicado más arriba a propósito de Antígona, esto es, su carácter esencialmente negador, su dependencia de un afuera que niega. Dejaba ver en concreto que esa actividad es siempre una negación de la muerte en tanto que otro del sentido (o de la unidad y de la necesidad), en tanto que absoluta negación del lógos o de la actividad del espíritu, en tanto que "negatividad abstracta" (GW 9, 244). Ese otro ya siempre presupuesto por la acción, por el ser del espíritu, es finalmente, pues, la muerte como pura o absoluta negación, como pura o absoluta inmediatez, en tanto que puro "no". Esto explica efectivamente que Hegel entienda que no hay nada, ninguna sustancia, ningún en-sí, ningún fundamento determinado, que preceda a la acción, del que la acción se pueda derivar, que concluya que ella es antes bien el principio absoluto, pero que a la vez afirme que su estar ya siempre referida a un presupuesto no es el efecto de un mero delirio que quepa "superar", que, efectivamente, esa necesidad de presuponer es real, está asentada en su propia esencia, y, en ese sentido, la precede. Se ve ahora claro: es la muerte lo único que precede a la acción, pero la muerte sólo en tanto que "no", la muerte sin nombre.

Por tanto se podía haber aprendido ya de la presentación, al comienzo del capítulo, del ser o el deber de la familia, que la acción es creación de sentido y negación de la muerte. Pero lo que la interpretación hegeliana de Antígona ha venido a explicitar es, a mi parecer, la necesidad de su fracaso, es decir, su carácter esencialmente trágico. Que la acción de Antígona llama al trágico destino significa que es necesario que lo que ella niega en su poner o su crear se vengue, retorne contra ella misma. La muerte negada, disfrazada de destino, no se vuelve solamente contra la ley o los dioses, contra el nombre o los nombres que la han negado y reprimido, mostrando su falta de universalidad o su carácter relativo, sino también contra la propia Antígona, contra el propio sí-mismo de la acción. Hegel escoge la Antígona de Sófocles porque, para él, deja ver que la necesidad de ello radica en que lo negado por la acción constituye su propio origen, dicho de otro modo, que la muerte a negar es siempre (la) propia y ciertamente en tanto que propio suelo (revelado como abismo). 
En efecto, Antígona sólo se constituye en esa acción, no es antes de la acción. El dar sentido del sí-mismo, como negación de la muerte, es por tanto un acto de supervivencia (como sí-mismo). Es el afirmarse por el que se constituye el propio símismo. Pero esto significa exactamente que a su base, en el lugar de su fundamento, antes de la sustancia y también del sí-mismo, sólo está el no de la muerte, que ella no reposa sobre nada (más), o que su principio es la muerte que niega. Justamente en tanto que acción positiva, en tanto que negación de la abstracta negatividad de la muerte, el espíritu nace de la muerte como pura negatividad: la fuerza para negar la muerte procede de la propia muerte. No se trata pues de que la acción niegue ya siempre la muerte como un otro extraño, de que ella sea su objeto, sino de que la necesidad de negarla que ella es está determinada por la propia muerte, y de que, por tanto, la fuerza activa o creadora del espíritu expresa esa muerte. Dicho de otro modo, la muerte es la negación del espiritu no sólo en tanto que, como absoluta in-mediatez, es su contrario, sino también en tanto que ella es el origen de la fuerza negadora que constituye el propio actuar (mediador) del espíritu, el origen del poder de la acción: ella pertenece al espíritu. El espíritu sólo es el hacerse cargo de la muerte para volverla contra la muerte o el volverse de la muerte contra $s^{\prime 23}$.

Es en este sentido en el que ese otro que trasciende a la acción sin ser sustancia determinada alguna, ese presupuesto suyo, no es en ningún caso un mero espejismo, un fantasma del que nos podamos deshacer para alcanzar la transparencia absoluta o la totalidad de sentido, sino que goza de una realidad positiva que, por tanto, por razones estructurales, obstruye la posibilidad misma de una totalidad de sentido ${ }^{24}$. Y es también desde aquí, desde el reconocimiento de este lazo esencial de la fuerza mediadora o de la acción espiritual a la inmediatez o a la negación del espíritu, desde donde Hegel puede hacerse cargo del engaño constitutivo de la acción, de la necesidad de que se oculte a sí misma. Porque la acción no puede saber que se niega (al negar su origen) en su mismo poner, por eso hay siempre en ella un ángulo muerto, un inconsciente: por eso Antígona no sabe que se contradice mientras actúa, ni Edipo que mata a su padre mientras lo mata. No hay acción sin inconsciente, o, dicho de otro modo, la autoconciencia - el sujeto de la acción- es siempre plegada, siempre entre dos tiempos. Hegel, pues, en la misma medida en que sabe que lo negado en toda acción es la propia muerte, sabe de la pertenencia del inconsciente, del "momento" no sabido, a toda acción. Pero ese mismo pliegue de la acción entre lo que sabe y lo que no sabe, ese tránsito entre el negar primero la muerte y ser negado luego por ella, señala el agujero que la acción está abriendo en la historia, el origen del tiempo.

23 No se pretende sugerir que se pueda traducir perfectamente la relación entre la acción del espíritu y la inmediatez de la muerte en Hegel por el vínculo entre el Dasein y el Sein que Heidegger establece, pero es inevitable reconocer en la intepretación que éste ofrece, al hilo del primer canto del coro de Antígona, de la "tragedia" del Dasein como el unheimliche modo de ser que sólo puede "abrir" el (propio) ser, crear historia y sentido, en la medida en que lo niega y que se expone así a la ruina, el parentesco con la comprensión hegeliana de la acción. Cf. M. Heidegger, Introducción a la metafísica. Barcelona, Gedisa, 2003, pp. 135-152.

24 Žižek basa su defensa del "materialismo" de Hegel precisamente en el carácter "positivo" o "real" de esta negación o de este límite del sentido: cf. S. Žižek, Menos que nada: Hegel y la sombra del materialismo dialéctico. Madrid, Akal, 2015, por ejemplo p. 265. 


\section{Inconsciente y destino: Grecia o el trauma de Occidente}

El "no" negado en la acción se vuelve por tanto contra ella, la lleva al fracaso o la niega radicalmente, porque es su mismo principio. Por eso el verbo elegido por Hegel para describir este resultado es "zu grunde gehen": ella fracasa al ser devuelta al "no" de la muerte como a su fundamento, al principio que ella ha negado como a su principio.

En la acción, el sí-mismo, la conciencia como fuerza unificadora de sentido, como lógos, se afirma negando la contingencia de la muerte al cubrirla de sentido, excluyéndola - en tanto que nada que constituye el propio fundamento- del ámbito de sentido al reprimirla en el in-consciente, como inconsciente. De manera que ese contragolpe de la acción en el que retorna la nihilidad de la muerte negada es también la confrontación del sí-mismo con el trauma, con la muerte reprimida, con el inconsciente en tanto que fundamento propio: en ella se disuelve en efecto su contraposición a su otro y, por ende, él mismo, la conciencia misma ${ }^{25}$. Sin duda la muerte en vida de Antígona, el descenso a la noche de la caverna, expone este momento de encuentro con la negación de la muerte, con la culpa reprimida, que supone toda acción en tanto que tragedia ${ }^{26}$. La (auténtica) acción reconduce, pues, al espíritu al origen de la historia, al sujeto al origen de su historia, a la reprimida negación del "no" de la muerte que la historia opera o que ella es. Pero es obvio que es precisamente este desenmascaramiento destructivo de la historia (dada) lo que abre la posibilidad de una historia nueva, de un tiempo nuevo. La contradicción autodestructiva de la acción es lo que la vuelve creadora, acción propiamente dicha ${ }^{27}$.

En las últimas páginas dedicadas a la acción griega, en aquellas en las que se anticipa cómo la sombra de Antígona acaba también con Creonte, con el Estado griego, y finalmente con la eticidad, explica Hegel cómo la sustancia ética encarnada paradigmáticamente en el Estado en tanto que identidad espiritual- se afirma necesariamente en la negación de la familia como fuerza natural inmediata, concretamente en la represión de la fuerza vital de la juventud; continúa mostrando cómo esta negación se traduce en la producción o generación de la fuerza militar que hace posible la afirmación del propio espíritu frente a la muerte que amenaza desde los otros pueblos, es decir, cómo el espíritu se afirma espiritualizando la muerte,

25 Comentando estos mismos pasajes insiste Derrida en Glas en el modo en que expresan la conciencia del vínculo necesario entre inconsciente y culpa. Por lo demás, sin llegar a retrotraer expresamente el destino a la muerte, este autor destaca la ironía de la risa con la que la inmediatez negada (la negatividad de la naturaleza/sustancia que retorna como destino) se vuelve finalmente contra el espíritu (aparentemente) vencedor. Cf. J. Derrida, Clamor. Madrid, La Oficina, 2015, esp. pp. 209-210. Podría parecer que Derrida suscribe la interpretación tradicional al comprender la fuerza que se impone sobre Antígona, el destino, como sustancia (antes que como muerte negada), pero es importante señalar que, en todo caso, en su lectura, esta sustancia es sustancia herida o, incluso, la herida misma de la sustancia. En este trabajo nos preguntamos por el origen de esa herida o, dicho de otro modo, por la razón por la que al desmoronamiento de Antígona sigue el de la propia sustancia y es esto lo que nos ha conducido al "no" de la muerte.

26 El desenlace de Antígona es tan significativo e importante para Lacan porque pone de manifiesto, en efecto, que el final de Antígona tiene la forma de una muerte doble, no meramente física, sino "simbólica": cf. J. Lacan, $E l$ Seminario de Jacques Lacan, Libro 7. Buenos Aires, Paidós, 2009, pp. 324-339.

27 Para una defensa del movimiento "plástico" del espíritu como apertura del tiempo: cf. C. Malabou, El porvenir de Hegel. Avellaneda, Palinodia, 2013, pp. 313-328. Žižek defiende precisamente que la filosofía de Hegel se determina por haber logrado dar cabida a la novedad de la historia, por dar cuenta de la posibilidad de reescribir el pasado, del modo en que toda acción lo hace: cf. S. Žižek, Menos que nada: Hegel y la sombra del materialismo dialéctico. Madrid, Akal, 2015, pp. 230-251. 
manipulándola o reorientándola; y acaba explicando cómo sin embargo la inmediatez natural (la muerte) negada se vuelve finalmente, en la guerra, también contra el propio Estado o contra el mundo ético en general: en definitiva cómo la negación de la muerte por parte del espíritu es un producirla "como un principio hostil" (GW 9, 259). La muerte vengativa aparece, pues, ahora, cuando se vuelve contra el mundo ético en general, como producida por el propio espíritu, por la propia acción represora (del Estado). Hegel reconoce entonces la muerte que viene de fuera como la fuerza hostil generada por la negación de la propia inmediatez, del propio ser-natural o de la propia muerte, que lleva a cabo la acción. El destino es también obra de la acción en tanto que ya siempre vuelta contra su propio presupuesto, finalmente contra la propia muerte (contra el "no" que reprime todo fundamento o todo presupuesto sustancial).

No se puede, por tanto, rechazar sin más la tesis de que la raíz de la tragedia reside para Hegel en la inmediatez de Grecia: ciertamente el desenlace trágico es convocado por la acción en la medida en que ella niega la inmediatez sin dejar de presuponerla o, en definitiva, de afirmarla. Hegel mismo lo explica diciendo que si la inmediatez destruye esta figura del espíritu, se impone sobre ella y la hunde finalmente, se debe a que ella misma, siendo espíritu, se quiere inmediata; a que es, en este sentido, inmediata. Porque reconoce el derecho de la inmediatez, no puede no ser afectada por ella, y acaba descomponiéndose frente a ella. Cuando llega a la guerra, antes incluso de perderla, ya se ha desmoronado, porque efectivamente la guerra significa que lo reconocido como lo que vale (por encima de toda ley y de todo sentido) es la fuerza natural, la contingencia y la inmediatez, la muerte del espíritu (cf. GW 9, 259-260).

Sin duda aquí encuentra la interpretación tradicional de Hegel un gran apoyo: Grecia cae en tanto en cuanto el espíritu es aquí aún sustancial. Comprendiéndose como unidad inmediata se quiere sustancia, naturaleza, y pierde por ello (de antemano) la batalla frente a ella; pero por eso mismo, para asegurar la victoria, para desterrar la tragedia, el espíritu sólo habrá de reconocerse como principio absoluto, saber su absolutez, saber que la inmediatez no es o que es sólo suya, puesta por él. La lectura tradicional, por tanto, de acuerdo con su interpretación del destino (trágico) como (vuelta de la) sustancia, puede afirmar entonces que la superación de la sustancia conllevará la de la tragedia.

Ahora bien, el presente trabajo ha tratado de mostrar que en este pasaje de la Fenomenología Hegel, reconociendo en el destino (trágico) de forma más o menos explícita la venganza de la muerte reprimida, reconoce a la base de la acción en general la nada de la muerte, la absoluta inmediatez, para defender entonces que el lazo de la acción (o del espíritu) a la inmediatez -aun cuando todos los nombres y formas que ésta adopta proceden sin duda del propio espíritu- es constitutivo, que la acción del espíritu depende necesariamente de la presuposición de la inmediatez. El desplazamiento respecto a la lectura tradicional puede parecer mínimo: se trata, en efecto, simplemente de decir que no es la inmediatez en sí la que causa la tragedia, sino más bien la dependencia de (el fantasma de) la inmediatez. Pero el pronóstico que de esta precisión se deriva es muy distinto al que habitualmente se concluye: en efecto, por muy atrás que dejemos la sustancia griega, si no podemos dejar de presuponer (engañándonos) alguna sustancia, puesto que esta presuposición (engañosa) se ha desvelado como el origen mismo de la acción, no parece ahora que quepa conjurar la tragedia, el carácter trágico de la acción hegeliana. 
La tragedia de Antígona le ha servido a Hegel, a mi parecer, para destapar la negación que oculta también el sujeto moderno. La pretensión de unidad de la acción, la necesidad con la que la acción se pone siempre como la acción de un sujeto, es sin duda constitutiva del sujeto moderno. Pero el texto de Hegel hace ver el sentido en el que esta posición es siempre una negación de la pluralidad y la contingencia de lo inmediato que está orientada a reemplazarlas por una unidad de sentido que, paradójicamente, se pretende absolutamente libre de esa inmediatez que es su otro, pero que, en este sentido, se postula también como sustancial o inmediata. Demuestra así que la presuposición de la inmediatez pertenece constitutivamente al espíritu y, por tanto, de rechazo, que no cabe pensar una acción (auténtica) en la que no se vaya a pique trágicamente la unidad del sujeto.

Decíamos al principio que Hegel presenta a Grecia como sustancia inmediata, pero que por el camino desmonta este mito. Pues bien, podemos decir ahora que tan importante como este rendimiento lo es el reconocimiento hegeliano de la necesidad de ese mito, del modo en el que el mito como tal -la posición de una unidad inmediata, tranquila como la muerte, externa y previa a la historia del espíritu- está atado al espíritu y a la acción. Es este reconocimiento, a mi juicio, el que coloca a Grecia en el centro de la Fenomenología, el que la hace aparecer como el otro negado por Occidente que sin embargo constituye su origen más íntimo, su fantasma y su trauma, su mito y su verdad, el pliegue de su saber. En esta medida este capítulo se convierte también en el espacio en el que Hegel obliga a la Modernidad a confrontarse con su Grecia como con su presupuesto, y en el que, a cambio, pero precisamente por ello, le abre la posibilidad de un tiempo nuevo, de trascender su propia historia. 